\title{
Promoting Physical Activity Through Kinesiology Teaching and Outreach: An Eye Toward the Future
}

\author{
Nancy I. Williams and Alan L. Smith
}

The stated mission of the American Kinesiology Association (AKA) is to "promote and enhance kinesiology as a unified field of study and advance its many applications" (American Kinesiology Association, n.d.). Pursuant to this mission, the annual AKA Leadership Workshop is focused on a timely and important topic, providing our members with opportunities to network, discuss, debate, and take valuable information back to their home departments. As has been our practice since 2015, we memorialize the "lessons learned" from our annual meeting in this special issue of Kinesiology Review. This issue is dedicated to the publication of scholarly, peer-reviewed manuscripts that capture the content presented at the AKA Leadership Workshop held in Tampa, FL, January 24-25, 2020. The theme of the meeting was "Promoting Physical Activity through Kinesiology Teaching and Outreach: An Eye toward the Future." The main workshop was preceded by two preworkshops focused on "Undergraduate Recruitment, Retention, and Career Trajectories" and "Facilitating and Highlighting Faculty and Student Research in Kinesiology." Over 200 academic leaders from 86 institutions participated in these leadership gatherings. The meeting featured exciting keynote presentations, thematic interactive presentations, brief communications, and round tables. We also featured our first "Dean's Forum," offering the opportunity for dean-suite leaders to learn about and discuss contemporary issues in kinesiology, and our second annual "Fireside Chat" with senior leaders in the field. In line with the diversity of AKA member units, the presentations and resulting articles demonstrate the originality, adaptability, and creativity of a range of approaches to promote physical activity through kinesiology teaching and outreach. They highlight the centrality of kinesiology academic units to the missions of their institutions, the many opportunities for transformative engaged scholarship, and the capacity for large-scale physical activity interventions that promote the lifelong adoption of healthy lifestyle habits.

This special issue on the 2020 AKA Leadership Workshop begins with a historical overview from Petruzzello and Box (2020) on the status of physical activity programming on university campuses, how this programming has changed over the years, and how kinesiology units might seize opportunities to address student mental health through efforts in the physical activity space. Petruzzello and Box astutely point out that, given the window of opportunity for developing students' lifelong behaviors, institutions of higher education need to work to create "wellness cultures that eliminate barriers to physical activity," including the consideration of revisiting general education physical activity requirements. Cardinal (2020) extends this thinking to explore the history and

Williams is with Pennsylvania State University, University Park, PA, USA. Smith is with Michigan State University, East Lansing, MI, USA. Williams (niw1@psu.edu) is corresponding author. specific issues related to implementing and sustaining a physical education general education requirement at colleges and universities. He asserts that through such requirements, kinesiology departments are uniquely suited to deliver programming that addresses longstanding concerns about college student health.

Brock, Beaudoin, Urtel, Hicks, and Russell (2020) and Griffin (2020) then provide examples of how universities can deliver sustainable physical activity programming. They speak to the challenges faced and the potential for cross-disciplinary, outdoor education as an alternative to traditional physical education curricula. These articles illustrate the current breadth and creativity of physical activity and physical education programming in higher education and provide insights into what the future of such programming could look like. Solmon et al. (2020) capture the content from their panel session at AKA with a comprehensive exploration of the historical role of physical education teacher education (PETE) in what are now departments of kinesiology, the current status of PETE programs, and what the future holds for the sustainability and growth of PETE programs. The authors dive into the complexities and challenges faced by kinesiology leaders in allocating resources, reconciling competing research priorities, and addressing low enrollments. Examples of program closures and program innovations are presented that provide important insights for kinesiology leaders.

Extending this conversation, Lounsbery and McKenzie (2020) then present a compelling case that school-based physical activity provides a critical opportunity to impact children's health and development. They argue that school administrators are in need of evidence-based information about physical activity benefits so that they may create policies to bolster physical activity programming. They emphasize that a public health focus in kinesiology and advocacy efforts by the AKA could facilitate this policy formation. Rounding out the focus on physical activity is the article by Winters (2020) on the key role that Exercise is Medicine on Campus ${ }^{\circledR}$ programming provides for kinesiology scholars and exercise professionals to contribute research, educate students and surrounding communities through outreach, and provide direct services for improving health.

Taken together, the AKA main workshop articles provide an in-depth, evidence-based perspective on the key role that kinesiology units play in educating students and communities about the benefits of physical activity and in directly improving human health and well-being through required and elective course offerings and outreach efforts. Combined with cutting-edge research on physical activity and human movement, it is clear that kinesiology units are having an impact when it comes to human health and wellness. Yet, despite being among the key players at many colleges and universities that tout "health and wellness" as foundational to their institutional planning, a nagging question arises: "Are we fully leveraging the opportunity to showcase our contributions in this physical activity space?" 
Success in the promotion of physical activity through kinesiology teaching and outreach would not be possible without attention to the "nuts and bolts" foundation of quality undergraduate teaching informed by the latest research. No matter the scholarly focus, an academic discipline will only be as strong as the students who carry on the work of education and knowledge generation that underpin the expansion and impact of the field. Accordingly, our AKA preworkshops focused on "Undergraduate Recruitment, Retention, and Career trajectories" and "Facilitating and Highlighting Faculty and Student Research in Kinesiology." Hamilton, Meaney, and Martinez (2020) provide insights into the use of an "equity audit" model to identify and combat inequities in academic programming and student achievement that stem from factors such as gender, race, and socioeconomic status. Kutz, Bopp, and Gravish Hurtack (2020) complement this discussion by describing strategies for data collection that help us understand barriers to student success and career placement. This article addresses curricular issues, academic advising models, and internship opportunities, and also gives examples of how to collect and learn from key student metrics. Importantly, it notes that students and parents are becoming increasingly proactive about selecting academic programs that provide the best preparatory path for graduate school acceptance and career planning. Last, but not least, the issue concludes with three papers focused on student research and scientific writing. Valdez and Liu (2020) tackle the important issue of undergraduate research in kinesiology in terms of student perceptions, strategies for success, and challenges unique to the field. Following on this theme, Russell (2020) outlines how Auburn's Future Scholars Summer Research Bridge Program works to provide unique research opportunities for undergraduates who aspire to attend graduate school. These efforts have improved graduate student diversity recruitment and retention processes and student success. Finally, we learn about "The Michigan Model" for incorporating a successful scientific writing course into the undergraduate kinesiology curriculum. Clark, Templin, and Lundberg (2020) describe the course and its importance to student success.

This special issue represents a valuable contribution through its timely attention to a topic at the heart of our success as an academic discipline - physical activity. Readers will find the articles to be innovative, well referenced, and reflective of the diversity of strong kinesiology programming from small to large institutions in the key areas of teaching, outreach, and research. There are numerous forward-looking opportunities and recommendations to be gleaned from the articles, offering us an eye to the future of physical activity promotion through kinesiology teaching and outreach. As scholars in kinesiology, this issue on physical activity naturally "covers a lot of ground" while inspiring us to continue to move forward, innovate, and learn from each other.

\section{Acknowledgments}

We wish to thank the authors for their excellent contributions to the special issue and for their responsiveness and timeliness during the review and final editing processes. We also wish to extend our deep appreciation to Tim Gavin, Chair of the AKA Publications Committee, for helping coordinate the review process. We are grateful for his efforts and those of the review team listed following in helping shape this special issue.

Timothy P. Gavin, Purdue University

Janet Buckworth, University of Georgia

A. Mark Williams, University of Utah

Amelia Mays Woods, University of Illinois at Urbana-Champaign

Gonzalo A. Bravo, West Virginia University

\section{References}

American Kinesiology Association. (n.d.). About AKA. Retrived from https://www.americankinesiology.org/SubPages/Pages/About.

Brock, S. J., Beaudoin, C., Urtel, M. G., Hicks, L. L., \& Russell, J. A. (2020). A constant balancing act: Delivering sustainable university instructional physical activity programs. Kinesiology Review, 9(4). doi:10.1123/kr.2020-0035

Cardinal, B.J. (2020). Promoting physical activity education through general education: Looking back and moving forward. Kinesiology Review, 9(4). 10.1123/kr.2020-0031

Clark, K. I., Templin, T. J., \& Lundberg, T. J. (2020). Scientific writing in kinesiology: The Michigan model. Kinesiology Review, 9(4). doi:10. 1123/kr.2020-0032

Griffin, K. (2020). Exploring the possibilities of outdoor/adventure education. Kinesiology Review, 9(4). doi:10.1123/kr.2020-0041

Hamilton, M., Meaney, K., \& Martinez, M. (2020). See, reflect, and act: Using equity audits to enhance student success. Kinesiology Review, 9(4). doi:10.1123/kr.2020-0033

Kutz, J. L., Bopp, M., \& Gravish Hurtack, L. A. (2020). What's holding them back? Informing retention and success of kinesiology undergraduates. Kinesiology Review, 9(4). doi:10.1123/kr.2020-0043

Lounsbery, M.A.F., \& McKenzie, T.L. (2020). American Kinesiology Association's role in promoting school physical activity policy. Kinesiology Review, 9(4). doi:10.1123/kr.2020-0029

Petruzzello S.J., \& Box, A.G. (2020). The kids are alright—right? Physical activity and mental health in college students. Kinesiology Review, 9(4). doi:10.1123/kr.2020-0039

Russell, J.A. (2020). Enhancing graduate student research, recruitment, and retention via a summer research experience. Kinesiology Review, 9(4). doi:10.1123/kr.2020-0037

Solmon, M. A., Graber, K. C., Woods, A. M., Williams, N. I., Templin, T. J., Price, S. L., \& Weimer, A. (2020). Physical education teacher education in kinesiology: Past, present, and future. Kinesiology Review, 9(4). doi:10.1123/kr.2020-0047

Valdez, I., \& Liu, T. (2020). Assessing student perceptions to enhance undergraduate research in kinesiology. Kinesiology Review, 9(4). doi: $10.1123 / \mathrm{kr} .2020-0038$

Winters, C. (2020). The promotion and implementation of Exercise is Medicine ${ }^{\circledR}$ in kinesiology. Kinesiology Review, 9(4). doi:10.1123/kr. 2020-0040 